\title{
Deficiency of the Eighth Component of Complement Associated With Recurrent Meningococcal Meningitis - Case Report and Literature Review
}

\author{
Daniela Dornelles Rosa, Alessandro C. Pasqualotto, \\ Maurício de Quadros and Sérgio Henrique Prezzi
}

\author{
Internal Medicine Department, Nossa Senhora da \\ Conceição Hospital, Porto Alegre, Rio Grande do Sul, \\ Brazil
}

\begin{abstract}
The authors report a case of deficiency of the eighth component of complement in a young adult with a history of three episodes of meningitis; one of them proved to be meningococcal. The literature was reviewed and meningitis due to Neisseria meningitidis strains causing disease in complement-deficient and complement-sufficient patients was demonstrated. Meningococcal disease may be the first manifestation of complement deficiency; screening for complement function must be considered for those with invasive meningococcal disease, with posterior evaluation of the components of the terminal pathway of complement.

Key-Words: Meningococcal disease, Neisseria meningitidis, complement deficiency.
\end{abstract}

The complement system consists of at least thirty proteins responsible for innate defenses against microorganisms; it is also involved in humoral immunity. To function properly, the integrity of all its proteins is necessary; deficiency of components can predispose to autoimmunity, especially systemic lupus erythematosus, and such deficiencies can leave the individual vulnerable to bacterial infections. An association of meningococcal infection with complement deficiency has been reported [1]. We report a case of recurrent meningococcal infections in a patient with deficiency of the eighth component of complement (C8). We also searched MEDLINE and LILACS (1990-2003) for studies linking complement deficiency and meningococcal disease.

Received on 17 April 2004; revised 07 July 2004.

Address for correspondence: Dr. Daniela Dornelles Rosa. Rua Honório Silveira Dias, 912/203. Zip code: 90550-050,Porto Alegre, Rio Grande do Sul, Brazil. Phone: (5551)3342-1886, Fax:(5551)3222-4451 E-mail: ddrosa@ terra.com.br

The Brazilian Journal of Infectious Diseases 2004;8(4):328-330 (C) 2004 by The Brazilian Journal of Infectious Diseases and Contexto Publishing. All rights reserved.

\section{Case Report}

A 21-year-old man was admitted to the emergency room due to fever, headache, vomiting, somnolence, irritability, thrills and myalgia that had begun 24 hours previously. There was no evidence of previous infection in the upper airways. He had a history of three other episodes of meningitis, one of them proved to be meningococcal. One of his brothers had also had meningococcal meningitis six months before. At physical examination, the patient was somnolent, disoriented and hypotensive, with petechiae in the legs and upper limbs, and he had conjunctival suffusion. A coalescent bleb with erythematous borders was observed in the lower lip. The patient had nuchal rigidity, and no papilledema was observed.

The chest radiograph showed alveolar consolidation in the left lower lobe, and a computed tomography scan of the skull was normal. Cerebrospinal fluid (CSF) was turbid, with 5300 cells $/ \mathrm{mm}^{3}$ (97\% neutrophils and $3 \%$ monocytes), 21 red blood cells $/ \mathrm{mm}^{3}, 74 \mathrm{mg} / \mathrm{dL}$ glucose $(100 \mathrm{mg} / \mathrm{dL}$ serum glucose), and $45 \mathrm{mg} / \mathrm{dL}$ protein. Microbiological exams of the CSF were negative, including cultures for mycobacteria and fungi. The anti-HIV serology was negative. 
The patient was treated with ceftriaxone, with good response. Neisseria meningitidis grew in blood culture; studies performed by the State Health Council (Secretaria de Saúde do Estado do Rio Grande do $\mathrm{Sul}$ ) indicated the $\mathrm{W}-135$ serotype.

Additional tests ruled out CSF fistulae. The serum immunoglobulin levels were normal. Reduced levels of total complement (CH100) were found, with normal values of $\mathrm{C} 3$ and $\mathrm{C} 4$. Evaluation of the terminal pathway of complement (C5 to C9) showed deficiency of the eighth component (C8) (Table 1). The patient was immunized against pneumococcus, meningococcus and Haemophilus influenzae. He had no further episodes of meningitis during the following 18 months. deficiency; this is the microorganism responsible for $75 \%$ to $85 \%$ of the infections identified in these patients [1]. Although infection by meningococcus has been associated with deficiency of any of the plasmatic proteins of complement, it more commonly involves deficiency of the terminal components of the complement pathway (C5 to C9); 39\% of these patients presented at least one episode $[3,4]$.

Meningococcal disease in patients with complement deficiency usually shows singular characteristics that suggest a need for further investigation [1]. While the average age at the onset of the first meningococcal infection is three years in the general population, and $56 \%$ occur before five years, the average age for complement deficiency

Table1. Serum levels of complement components in a patient with recurrent meningococcal meningitis

\begin{tabular}{ccc}
\hline Complement fraction & Observed values & Reference values \\
\hline CH100 & $0.64 \mathrm{U} / \mathrm{mL}$ & $63-145 \mathrm{U} / \mathrm{mL}$ \\
C3 & $118 \mathrm{mg} / \mathrm{dL}$ & $75-140 \mathrm{mg} / \mathrm{dL}$ \\
C4 & $20 \mathrm{mg} / \mathrm{dL}$ & $10-34 \mathrm{mg} / \mathrm{dL}$ \\
C5 & $220 \mathrm{mg} / \mathrm{dL}$ & $130-230 \mathrm{mg} / \mathrm{dL}$ \\
C6 & $926 \mathrm{mg} / \mathrm{dL}$ & $800-2400 \mathrm{mg} / \mathrm{dL}$ \\
C7 & $825 \mathrm{mg} / \mathrm{dL}$ & $400-1400 \mathrm{mg} / \mathrm{dL}$ \\
C8 & $60 \mathrm{mg} / \mathrm{dL}$ & $600-1600 \mathrm{mg} / \mathrm{dL}$ \\
C9 & $1057 \mathrm{mg} / \mathrm{dL}$ & $600-2000 \mathrm{mg} / \mathrm{dL}$ \\
\hline
\end{tabular}

\section{Discussion}

The common goal of the activation of the different pathways of complement (classic, alternative or from lectin) is the deposit of $\mathrm{C} 3 \mathrm{~b}$ on the target recognized as foreign, and later activation of the membrane attack complex (terminal components of complement, C5 to C9), increasing the immune response, and resulting in opsonization of the target particle [2].

The importance of the complement system in the defense against meningococcus is illustrated by the higher risk (about 10,000 times higher) of meningococcal disease in patients with complement patients is 17 years, and only $10 \%$ of the cases occur before five years of age. Previous infection with meningococcus in this group of immunodeficient patients does not reduce the risk of new episodes; relapses occur in $7.6 \%$ of those with deficiency of C5-C9, and recurrent disease (new infection more than one month after a previous episode) occurs in $45 \%$. These frequencies are 10 and 150 times higher than those found in the general population, respectively. This could be explained in part by the fact that antibodies against subcapsular antigens, although bactericidal and protective, are poor opsonins; they offer little protection in patients with 
complement deficiency, as these patients do not have the proteins needed for the expression of bactericidal activity [5].

Another peculiar aspect is that, despite the high risk for meningococcal disease, there is a 5 to 10 -fold decrease in the probability of death due to this disease in patients with complement deficiency, when compared to the general population [1]. Therefore, the same condition that predisposes to infection seems to protect against the lethal consequences of the disease, suggesting that an exacerbated response from the host is the main factor associated with the clinical manifestations and the outcome of the disease [6]. This hypothesis is supported by Brandtzalg et al., who have found an association between the extent of complement activation and mortality due to meningococcal disease [7]. Other manifestations of complement deficiency that may be relevant include less severe disease, higher capacity to tolerate the endotoxins [7] and less damage to host cells. The theory that low numbers of microorganisms are sufficient to provoke systemic meningococcal disease seems attractive, although it has not been proven [8].

Unusual meningococcal serogroups (particularly Y, W-135 and X) usually infect patients with complement deficiencies [1,3], and the frequency of these among patients with meningococcal disease caused by these serogroups is also increased [9]. In a study of 7732 patients with meningococcal disease [10], the prevalence of complement deficiency was $3 \%$. When patients with unusual serotypes were examined, the prevalence of any complement deficiency was $33 \%$, and the prevalence of C8 deficiency was $23 \%$. Pulmonary involvement is common in infections with $\mathrm{W}-135$ serotype [11], as we found in our patient.

\section{Conclusion}

Evaluation for immunodeficiency is not indicated for most patients with bacterial meningitis, particularly those who had been healthy, with no recurrent infection and without risk factors for infection by the human immunodeficiency virus. Meningococcal disease may be the first manifestation of complement deficiency; screening for complement function $(\mathrm{CH} 100)$ must be considered for those with invasive meningococcal disease, with further evaluation of the components of the terminal pathway of complement (C5 to C9).

\section{References}

1. Figueroa J.E., Densen P. Infectious diseases associated with complement deficiencies. Clin Microbiol Rev 1991;4:359-95.

2. Walport M.J. Complement. First of two parts. N Engl J Med 2001;344:1058-66.

3. Ross S.C., Densen P. Complement deficiency states and infection: Epidemiology, pathogenesis and consequences of neisserial and other infections in an immune deficiency. Medicine (Baltimore) 1984;63:243-73.

4. Overturf G.D. Indications for the immunological evaluation of patients with meningitis. Clin Infect Dis 2003;36:189-94.

5. Andreoni J., Käyhty H., Densen P. Vaccination and the role of capsular polysaccharide antibody in prevention of recurrent meningococcal disease in late complement component-deficient individuals. J Infect Dis 1993; $168: 227-31$.

6. Platonov A.E., Beloborodov V.B., Vershinina I.V. Meningococcal disease in patient with late complement component deficiency: studies in the U.S.S.R. Medicine (Baltimore) 1993;72:374-92.

7. Brandtzaeg P., Mollnes T.E., Kierulf P. Complement activation and endotoxin levels in systemic meningococcal disease. J Infect Dis 1989; 160:58-65.

8. Fijen C.A.P., Kuijper E.J., Dankert J., et al. Characterization of Neisseria meningitidis strains causing disease in complement-deficient and complement-sufficient patients. J Clin Microbiol 1998;36:2342-5.

9. Fijen C.A., Kuijper E.J., Hannema A.J., et al. Complement deficiencies in patients over ten years old with meningococcal disease due to uncommon serogroups. Lancet 1989;2:585-8.

10. Fijen C.A., Kuijper M.T., Bulte M.T., et al. Assessment of complement deficiency in patients with meningococcal disease in the Netherlands. Clin Infect Dis 1999;28:98105.

11. Stephens D.S., Hajjeh R.A., Baughman W.S., et al. Sporadic meningococcal disease in adults: results of a 5-year population-based study. Ann Intern Med 1995;123:937-40. 